\title{
Review
}

\section{BCL2A1: the underdog in the BCL2 family}

\author{
M Vogler ${ }^{*, 1}$
}

B-cell lymphoma 2 (BCL2) proteins are important cell death regulators, whose main function is to control the release of cytochrome $c$ from mitochondria in the intrinsic apoptotic pathway. They comprise both pro- and anti-apoptotic proteins, which interact in various ways to induce or prevent pore formation in the outer mitochondrial membrane. Due to their central function in the apoptotic machinery, BCL2 proteins are often deregulated in cancer. To this end, many anti-apoptotic BCL2 proteins have been identified as important cellular oncogenes and attractive targets for anti-cancer therapy. In this review, the existing knowledge on B-cell lymphoma 2-related protein A1 (BCL2A1)/Bcl-2-related gene expressed in fetal liver (Bfl-1), one of the less extensively studied anti-apoptotic BCL2 proteins, is summarized. BCL2A1 is a highly regulated nuclear factor $\kappa B$ (NF- $\kappa B$ ) target gene that exerts important pro-survival functions. In a physiological context, BCL2A1 is mainly expressed in the hematopoietic system, where it facilitates survival of selected leukocytes subsets and inflammation. However, BCL2A1 is overexpressed in a variety of cancer cells, including hematological malignancies and solid tumors, and may contribute to tumor progression. Therefore, the development of small molecule inhibitors of BCL2A1 may be a promising approach mainly to sensitize tumor cells for apoptosis and thus improve the efficiency of anti-cancer therapy.

Cell Death and Differentiation (2012) 19, 67-74; doi:10.1038/cdd.2011.158; published online 11 November 2011

\section{Facts}

- B-cell lymphoma 2-related protein A1 (BCL2A1) is particularly important in the hematopoietic system and exerts its anti-apoptotic function by sequestering pro-apoptotic B-cell lymphoma 2 (BCL2) proteins.

- In different types of cancer including leukemia and lymphoma an increased expression of BCL2A1 was described.

- Enhanced expression of BCL2A1 can result in resistance to chemotherapeutic drugs.

- Nuclear factor $\kappa \mathrm{B}$ (NF- $\kappa \mathrm{B})$ is an important inducer of BCL2A1 expression.

\section{Open Questions}

- Is BCL2A1 induced upon inflammasome formation and important for cellular survival during inflammation?

- Does BCL2A1 have a function or interaction partners outside of the BCL2 family?

- Which E3 ligase mediates the proteasomal degradation of BCL2A1?

- Can small molecule inhibitors of BCL2A1 be used clinically as anti-cancer treatments?

\section{Overview of the BCL2 Family}

Apoptosis or programmed cell death can be either triggered by death receptor ligation on the cell surface (the extrinsic pathway) or alternatively upon cellular stress at the mitochondria (the intrinsic pathway). While death receptor ligation results in the formation of the death-inducing signaling complex, in the intrinsic pathway the release of cytochrome $c$ from the mitochondrial intermembrane space into cytosol triggers the formation of the apoptosome and caspase-9 activation. The extrinsic pathway appears to be mainly regulated by the caspase-8 inhibitory protein FLIP, which was first identified by Jurg Tschopp and co-workers. ${ }^{1,2}$ However, in the intrinsic pathway the critical step is the release of cytochrome $c$ from mitochondria, which is regulated by the BCL2 proteins. ${ }^{3}$ The BCL2 protein family consists of both pro- and anti-apoptotic members, which all share sequence homology in their BCL2 homology $(\mathrm{BH})$ domains. The pro-apoptotic proteins comprise the multidomain proteins $\mathrm{BAX}$ and $\mathrm{BAK}$ as well as the $\mathrm{BH} 3-$ only proteins. By forming a pore in the outer mitochondrial membrane, BAX and BAK have an essential role in mediating cytochrome $c$ release and thus their activation is tightly controlled by the other BCL2 proteins. The $\mathrm{BH} 3-$ only proteins are highly regulated on the transcriptional and post-transcriptional level and can be induced by multiple stress signals. ${ }^{4}$ Upon activation, the $\mathrm{BH}$ only proteins can activate $\mathrm{BAX}$ and $\mathrm{BAK}$, thereby triggering cytochrome $c$ release and apoptosis. The main function of the anti-apoptotic BCL2 proteins is to counteract the activation of $B A X$ and BAK. Thus they can either inhibit BAX and BAK directly, or sequester and inactivate BH3-only proteins. So far,

\footnotetext{
${ }^{1}$ MRC Toxicology Unit, University of Leicester, Leicester, UK

${ }^{*}$ Corresponding author: M Vogler, University of Leicester, Hodgkin Building, LE1 9HN, Leicester, UK. Tel: + 44116 2525569; Fax: +44 116 2525616;

E-mail: mv62@le.ac.uk

Keywords: BCL2A1; BCL2; apoptosis; cancer

Abbreviations: BCL2, B-cell lymphoma 2; BCL2A1, B-cell lymphoma 2-related protein A1; BH, BCL2 homology; Bfl-1, Bcl-2 related gene expressed in fetal liver; GRS, Glasgow rearranged sequence; NF- $\kappa$ B, nuclear factor $\kappa \mathrm{B}$; TNF, tumor necrosis factor; NuBCP-9, Nur77-derived BCL2-converting peptide with nine amino acids; PRP, pattern recognition receptor

Received 26.5.11; revised 07.10.11; accepted 07.10.11; Edited by G Melino; published online 11.11.11
} 
multiple anti-apoptotic BCL2 proteins have been described, namely BCL2, BCL-X, , BCL-w, MCL1, BCL-B and BCL2A1 (also called $\mathrm{Bcl}-2$ related gene expressed in fetal liver (Bfl-1) or Glasgow rearranged sequence (GRS)). Many of these proteins have been identified as important cellular oncogenes that not only promote tumorigenesis but also contribute to the resistance to chemotherapeutic drugs and failure of anti-cancer treatments. The importance of BCL2 proteins for cancer progression has recently been highlighted by a genome-wide screen, which identified BCL- $X_{L}$ and MCL1 as highly amplified in cancer cells. ${ }^{5}$ However, although BCL2, $B C L-X_{L}$ and $M C L 1$ are well studied, less is known about the exact function of BCL-W, BCL-B and BCL2A1. Here, the published knowledge on BCL2A1 is reviewed with a particular focus on its role in cancer biology.

\section{Structure of BCL2A1}

The human gene $B C L 2 A 1$ is located on chromosome $15 q 24.3$ and contains three exons. ${ }^{6,7}$ The most common mRNA for $B C L 2 A 1$ is transcribed from exons 1 and 3 , resulting in a 175 amino-acid protein, which consists of nine $\alpha$-helices. Crystal structures of BCL2A1 in complex with BH3-peptides (Protein Data Bank: 3MQP, 3I1H, 2VM6) revealed that it displays a similar hydrophobic groove as found on all related anti-apoptotic BCL2 proteins. ${ }^{8}$ In addition, it contains four $\mathrm{BH}$-domains $\left(\mathrm{BH}_{1-4)}\right.$ (Figure 1). In contrast to other anti-apoptotic BCL2 proteins, BCL2A1 does not display a well-defined C-terminal transmembrane domain. However, its C-terminus is of importance for the anti-apoptotic function and the subcellular localization of BCL2A1. ${ }^{9}$

An additional isoform named Bfl-1S was described, which contains all three exons with an early stop codon in exon $3 .^{10}$ This isoform is expressed in lymph nodes and spleen and the resulting 163 amino-acid protein has an altered and shorter C-terminus, which results in nuclear rather than cytoplasmic or mitochondrial localization. However, the physiological function of this alternative splice variant is only poorly understood and whether there is a nuclear function for $\mathrm{Bfl}-1 \mathrm{~S}$ remains to be investigated.

Mouse Bcl2a1 contains two exons and is encoded on chromosome 9 . In contrast to the human gene, it contains four copies (A1-a, A1-b, A1-c, A1-d). Although A1-a, A1-b and $A 1-d$ are nearly identical, $A 1-c$ contains a point mutation resulting in a truncated transcript. ${ }^{11}$ Overall, murine and human BCL2A1 share $72 \%$ amino-acid identity and display very similar structures ${ }^{8,12}$ (Figure 1).

\section{Interaction Partners of BCL2A1}

A shared characteristic of all anti-apoptotic BCL2 proteins is the sequestration of pro-apoptotic BCL2 proteins including the

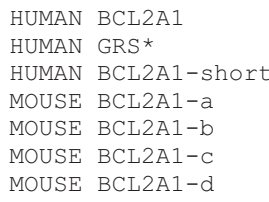

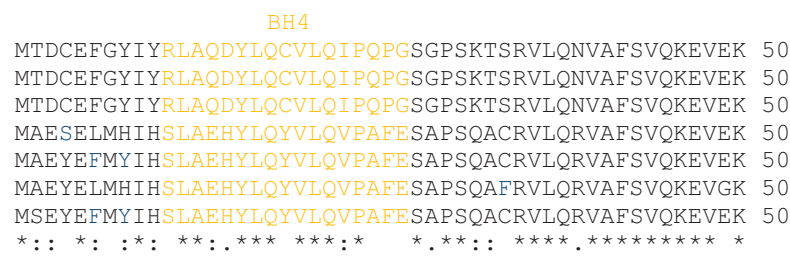

$\mathrm{BH} 3$

NLKSCLDNVNVVSVDTARTLFNQVMEKEFEDGIINWGRIVTIEAFEGILI 100 NLKSCLDNVNVVSVDTARTLPTOVME F FE DCT TNACRTVRTFA FECILI 100 NLKSCLDNVNVVSVDTARTLFNQVME KEFEDGIINWGRIVTIEAEEGILI 100 NLKSYLDDFHVES IDTARI IFNQVMEKEFEDGINWGRIVTIEAFGGVLL 100 NLKSYLDDFHVES IDTARI IFNQVME KEFEDGIINWGR IVTIFAFGGVLL 100 NLKSYLDDFHVESIDTTRI IFNQVME FFFDGTTNWGRTVTTFAFGCVLL 100 NLKSYLDDFHVESIDTARIIFNQVME KEFEDGIINWGR IVTIFAFGGVLL 100

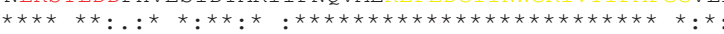

KKLLRQQIAPDVDTYKEISYFVAEFIMNNTGEWIRQNGGWENGFVKKFEP 150 KKLLRQHIAPDVDTYKEISYFVAEFIMNNTGEWIRQNGGWENGFVKKFEP 150 KKLLROOIAPDVDTYKEISYFVAEFIMNNTGEWIRONGGWGKWHNHTP-- 148 KKLPQEQIALDVCAYKQVSSFVAEFIMNNTGEWIRQNGGWEDGEIKKFEP 150 KKLPQEQIALDVGAYKQVSSFVAEFI INNTGEWIRRNGGWEDGEIKKFEP 150

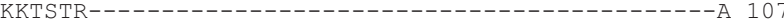
KKLPOEQIALDVGAYKQVSSFVAEFIMNNTGEWIRRNGGWEDGFIKKFEP 150 $\star \star$

KSGWMTFLEVTGKICEMLSLLKOYC 175 KSGWMTFLEVTGKICEMLSLLKQYC 175 ----MLVESVAHKKRKMAL----- 163 KSGWLTFLQMTGQIWEMLFLLK--- 172 KSGWLTFLOMTGOFWEMLFLLK--- 172 DCPGCTCLQTSFQFWGRIHNE---- 128 KSGWLTFLQMTGQIWEMLFLLK--- 172

Figure 1 Protein sequence alignment of human and mouse BCL2A1. Besides full-length human BCL2A1 (Q16548), the variant GRS ${ }^{49}$ and the alternative splicing isoform BCL2A1-short/Bfl1-S (Q86W13) are displayed. Mouse BCL2A1 is encoded on four copies named A1-a (O07440), A1-b (O55177), A1-c (O55178) and A1-d (O55179). Protein IDs refer to the UniProt knowledgebase. Alignment was done using ClustalW2 from the European Bioinformatics Institute (Cambridge, UK). The BH domains as well as intraspecies single amino-acid variants are highlighted by color 
multidomain proteins $B A K / B A X$ and the $B H 3-o n l y$ proteins. The interaction of BCL2A1 with $B A X$ and $B A K$ has been investigated in many different studies, with rather conflicting results. In this regard, BCL2A1 has been found to bind both BAK and BAX in yeast-two-hybrid screens. ${ }^{13-15}$ Recombinant BCL2A1 showed a weak interaction with BAX and not with BAK in a GST-pulldown assay, but binding to both BAK and BAX BH3-peptides by fluorescence polarization assay with an $\mathrm{EC}_{50}$ of 45.5 and $17.3 \mathrm{nM}$, respectively ${ }^{16}$ (Figure 2). In mammalian cells, overexpressed mouse BCL2A1 was found to bind BAK but not BAX. ${ }^{17}$ Similarly, human BCL2A1 selectively bound to BAK and overexpressed but not endogenous BAX. ${ }^{18}$ However, others have not found either interaction with BAK or BAX. ${ }^{19,20}$ Thus, it appears that in cellular systems, BCL2A1 binds to BAK more prominently than to $B A X$, and contrasting results reported in the individual studies may be explained by the investigated expression system and different assay sensitivities.

In regards to binding of $\mathrm{BH} 3-$ only proteins, it appears clear that BCL2A1 interacts with tBID. ${ }^{18,19} \mathrm{BH} 3$ profiling indicated that among the $\mathrm{BH} 3-$ only proteins, BCL2A1 binds only to BIM (Figure 2), BID and PUMA BH3-peptides. ${ }^{21}$ Using a different approach, binding of BCL2A1 to BH3-peptides was investigated by fluorescence polarization assay, when BCL2A1 was found to interact with BIM, BID and PUMA, but also to a weaker extent with BIK, HRK and NOXA (Figure 3), indicating a similar binding profile as displayed by MCL $1 .{ }^{22}$ Binding of BCL2A1 and NOXA by fluorescence polarization assay was confirmed in a different study. ${ }^{23}$ Therefore, in terms of binding
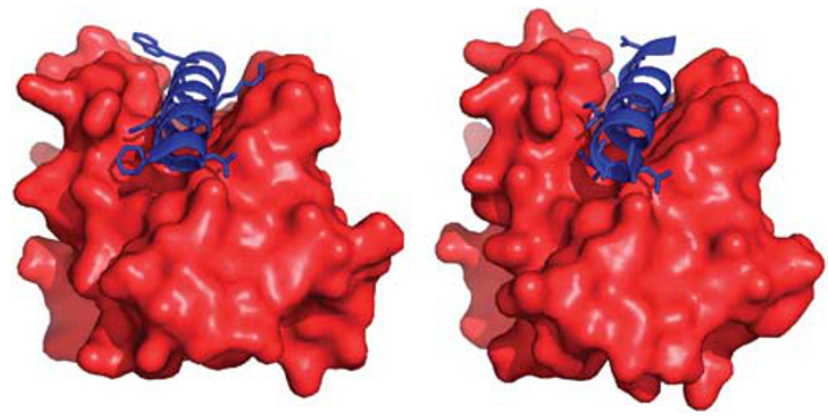

Figure 2 Structure of $B C L 2 A 1$ in complex with $B H 3$ peptides. Binding of human BCL2A1 (in red) to BIM (left, PDB: 2VM6) and BAK (right, PDB: 3l1H) BH3peptides was illustrated in Pymol (Schrodinger Inc., Portland, OR, USA). The residues of the $\mathrm{BH} 3$-peptides (blue) directly interacting with the hydrophobic pockets of BCL2A1 are displayed as sticks to $\mathrm{BH} 3-$ only proteins, BCL2A1 is often grouped together with $M C L 1$, whereas BCL2, BCL- $X_{L}$ and $B C L-W$ form another group capable of binding BAD but not NOXA. ${ }^{24}$

HA-tagged overexpressed BCL2A1 also interacts with the BH3-like protein Beclin-1, thus potentially contributing to inhibition of autophagy. ${ }^{25}$ In addition, an interaction of BCL2A1 with Nur77-derived BCL2-converting peptide with nine amino acids (NuBCP-9) has been described. In that study, NuBCP-9 converted BCL2 into a pro-apoptotic molecule by binding to its loop region, which resulted in exposure of the BCL2 BH3 domain. ${ }^{26}$ However, as that study was focussed on BCL2, no data for BCL2A1 other than the co-immunoprecipitation of the tagged proteins were reported, and it remains to be proven whether, by analogy to BCL2, binding of NuBCP-9 may also convert BCL2A1 into a pro-apoptotic protein (Figure 3).

\section{Regulation of BCL2A1}

The transcription of $B C L 2 A 1$ is highly regulated. It was originally identified by Prystowsky's group ${ }^{27,28}$ as a gene induced by GM-CSF and LPS, suggesting that it may be an early-response gene. Later on it was found to be inducible by tumor necrosis factor $\alpha^{29,30}$ and identified as an NF- $\kappa \mathrm{B}$ target gene. ${ }^{31}$ Simultaneously, $B C L 2 A 1$ transcription was reported to be induced in response to antigen receptor stimulation. ${ }^{32}$ Since then, several reports have demonstrated the importance of $B C L 2 A 1$ upregulation for B-lymphocyte survival upon CD40 signaling. ${ }^{33-35}$ In addition to CD40 signaling, PI3K and ERK signaling initiated by ICAM-1 binding have been found to induce NF- $\kappa \mathrm{B}$ and subsequently $B C L 2 A 1$ expression ${ }^{36}$ (Figure 4). Interestingly, both hyperoxia ${ }^{37}$ and low levels of reactive oxygen species ${ }^{38}$ were described to increase $B C L 2 A 1$ transcription, possibly in an NF- $\kappa$ B-dependent manner. In both situations, BCL2A1 exerted a pro-survival function to prevent cell death.

Besides NF- $\kappa \mathrm{B}$, several other transcription factors have been implicated in $B C L 2 A 1$ transcriptional regulation, including all-trans retinoic acids ${ }^{39,40}$ or retinoic $X$ receptor agonists, ${ }^{41}$ the (-EX5/-KTS) isoform of WT- $1^{42}$ and the transcriptional enhancer Spi-1/PU.1. ${ }^{43}$ On the other hand, $B C L 2 A 1$ transcription is repressed by the plasma cell transcription factor PRDI-BF1/Blimp- $1^{44}$ (Figure 4).

In addition to the transcriptional regulation, BCL2A1 is also controlled at the post-translational level. In this regard, $B C L 2 A 1$ is regulated by the ubiquitin/proteasome pathway a

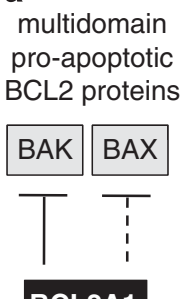

BCL2A1 b

pro-apoptotic BH3-only proteins

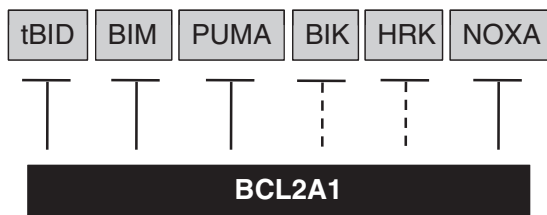

C

other interaction partners

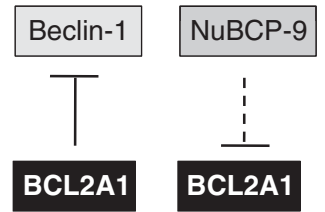

Figure 3 Interaction partners of BCL2A1. Binding by BCL2A1 can inhibit or neutralize pro-apoptotic multidomain BCL2 proteins (a) and BH3-only proteins (b). In addition, BCL2A1 can sequester Beclin-1 (c). Binding by NuBCP-9 may inhibit the anti-apoptotic function of BCL2A1 


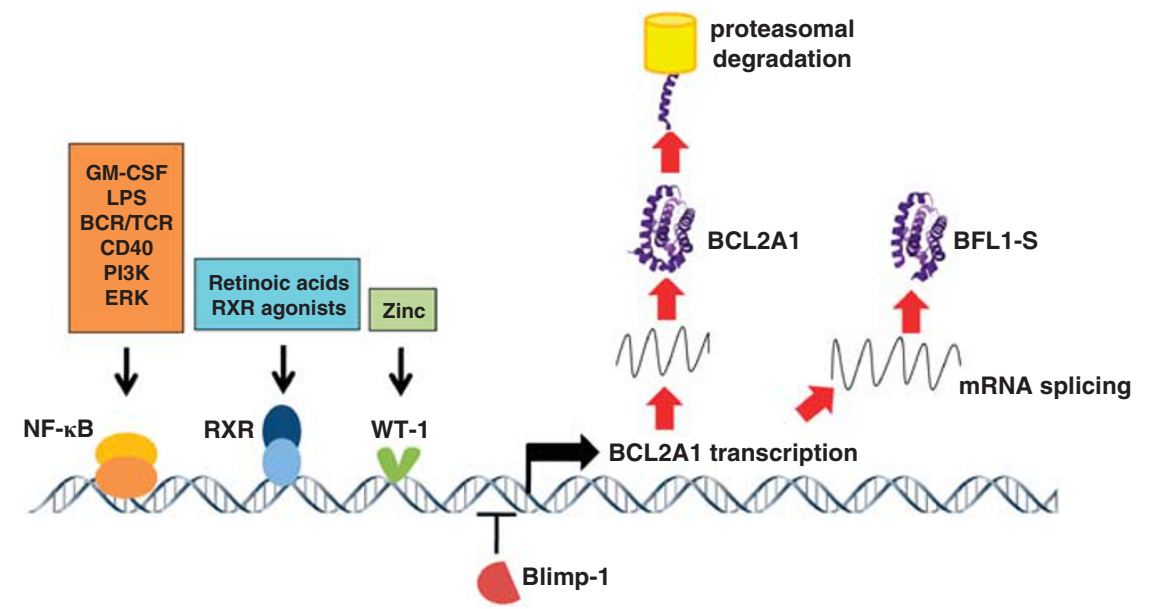

Figure 4 Regulation of BCL2A1. BCL2A1 transcription is induced by NF- $\kappa$ B, retinoic X receptors (RXR) and WT-1, but repressed by the plasma cell transcription factor Blimp-1. Differential splicing can result in transcription of either BCL2A1 or BFL1-S. The stability of BCL2A1 protein is regulated by proteasomal degradation

and undergoes constitutive proteasome-mediated turnover, resulting in a short half-life of the protein. ${ }^{45,46}$ However, so far no E3-ligase for BCL2A1 has been identified. Whether the proteasomal degradation of BCL2A1 can also be controlled by certain pro-or anti-apoptotic stimuli, for example, via phosphorylation events, has not been investigated yet but may provide an extra layer of regulation. In addition to the proteasomal turnover, cleavage by $\mu$-calpain can convert BCL2A1 from an anti- into a pro-apoptotic protein. ${ }^{46}$

\section{Expression and Function of BCL2A1 in Normal Tissues}

There are conflicting reports on the tissue distribution of BCL2A1, possibly due to differences in the expression pattern of mouse and human BCL2A1 mRNA. Although mouse mRNA appears to be mainly expressed in hematopoietic cells, in humans a more widespread tissue distribution was found, also including lung, small intestine, testis and smooth muscle cells. ${ }^{30}$ The human BCL2A1 gene was identified and cloned by three different groups using distinct and independent approaches. Firstly, it was identified from fetal liver and thus named ' $\mathrm{Bcl}-2$ related gene expressed in fetal liver' (Bfl-1), highlighting its involvement in early hematopoiesis. ${ }^{47}$ Secondly, it was discovered as a gene induced upon cytokine treatment in activated endothelial cells. ${ }^{30}$ This study indicated that BCL2A1 exhibits an important pro-inflammatory function. Further support for the importance of BCL2A1 expression in endothelial cells was provided by the findings that monocytes can induce BCL2A1 upregulation in endothelial cells to protect them from cell death. ${ }^{48}$ Thirdly, BCL2A1 was found to be involved in a chromosomal rearrangement in a chronic myeloid leukemia patient linking it to fibroblast growth factor 4 , thus also named GRS. ${ }^{49}$ This rearranged BCL2A1 displayed three mutations in sequence, the importance of which is not clear (Figure 1). Mouse Bcl2a1 mRNA is induced during myeloid differentiation, ${ }^{28}$ mast cell activation upon an allergic reaction, ${ }^{50-52}$ lymphocyte development, ${ }^{53-55}$ and lymphocyte and macrophage activation, ${ }^{28,56}$ emphasizing the importance of BCL2A1 in the immune system. BCL2A1 was downregulated in plasma cells, ${ }^{57,58}$ possibly due to its transcriptional repression by plasma cell transcription factors. ${ }^{44}$

The identification of $\mathrm{BCL} 2 \mathrm{~A} 1$ as an $\mathrm{NF}-\kappa \mathrm{B}$ target gene further indicates an important function of BCL2A1 during inflammation. Inflammation is an important part of the innate immune response and involves the ligation of pattern recognition receptors (PRPs) including the NOD-like receptors that participate in the formation of the inflammasomes, first described by Jurg Tschopp and colleagues. ${ }^{59,60}$ One of the major signaling pathways induced by PRPs is the activation of NF- $\kappa \mathrm{B}$ and the upregulation of pro-inflammatory genes. Thus it appears possible that formation of inflammasomes may also induce the expression of BCL2A1, thus contributing to the survival of the pro-inflammatory cells during an immune response.

Interestingly, a physiological function of BCL2A1 in mammary cell differentiation has been reported. In this regard, $B c / 2 a 1 \mathrm{mRNA}$ is upregulated in pregnant mice upon weaning, and pregnancy prevents mammary gland involution by apoptosis, a function that may be mediated by the increased BCL2A1 levels. ${ }^{61}$ However, there may be differences in the regulation of $\mathrm{Bcl} 2 \mathrm{a} 1$ during mammary gland involution in different mouse strains. ${ }^{62}$

\section{Genetic Modification of Bcl2a1 in Mice}

To further study the function of BCL2A1, transgenic and knockout mice have been generated. Lymphocyte-specific transgenic $E \mu-B c l 2 a 1$ mice show extended survival of thymocytes and early B-cells together with a prolonged pro$B$ stage, indicating an impairment of pro- to pre-B-cell transition due to BCL2A1 overexpression. ${ }^{63}$ The importance of BCL2A1 for T-cell survival was confirmed in lck-Bcl2a1 transgenic mice, which displayed increased BCL2A1 expression predominantly in T-cells. Overexpression of BCL2A1 resulted in higher $\mathrm{T}$-cell numbers in the thymus and spleen as well as reduced apoptosis. ${ }^{64}$ In a similar study, CD2-Bc/2a1 transgenic mice showed increased thymic cellularity due to enhanced survival of $\mathrm{CD}^{+}{ }^{+} \mathrm{CD}^{+}{ }^{+}$double positive T-cells. ${ }^{65}$ Interestingly, transgenic $\mathrm{Bcl} 2 \mathrm{a} 1$ mice do not develop 
lymphomas, ${ }^{63}$ suggesting that in contrast to other antiapoptotic proteins like BCL2, ${ }^{66}$ BCL2A1 overexpression alone is not sufficient to induce tumorigenesis.

Although the genetic deletion of $\mathrm{Bcl}-\mathrm{X}$ and $\mathrm{Mcl}-1$ is lethal, ${ }^{67,68}$ the overall phenotype of $B c / 2 a 1-k n o c k o u t$ animals appears to be rather normal with only hair loss observed during ageing. ${ }^{69}$ However, genetic deletion of $B c / 2 a 1$ is complicated by the occurrence of multiple gene copies, which are differentially expressed in different cell types. ${ }^{11}$ The genetic deletion of one copy of the murine Bcl2a1 gene (A1-a) resulted in enhanced apoptosis in peripheral blood neutrophils. ${ }^{69}$ In addition, a reduced response to allergenic stimuli was found and Bcl2a1-a knockout mice displayed $50 \%$ less mast cells in the skin upon allergenic challenge. ${ }^{50}$ In order to silence multiple copies of the Bcl2a1 gene, a conditional transgene-driven shRNA for Bcl2a1 was used to simultaneously knock down A1-a, A1-b and A1-d. However, the RNAi efficiency varied between tissues, and although efficient knockdown of the Bcl2a1 mRNA was achieved in thymocytes, the gene silencing was inefficient in mature lymphocytes and no obvious phenotype was found. ${ }^{70}$ Taken together, the studies performed with transgenic and knockout mice support a pro-survival function of BCL2A1 in the hematopoietic system especially during maturation and differentiation of specific lymphocytes subsets.

\section{Expression of BCL2A1 in Cancer}

Due to its important function in the hematopoietic system it is not surprising that increased expression of BCL2A1 is associated with different forms of leukemia and lymphoma (Table 1). As compared with healthy controls, overexpression of BCL2A1 mRNA was described in acute lymphoblastic and chronic lymphocytic leukemia. ${ }^{71}$ In chronic lymphocytic leukemia, high BCL2A1 expression was found to correlate with more severe cases, indicating a prognostic function of $\mathrm{BCL} 2 \mathrm{~A} 1$ in this very heterogeneous patient group. ${ }^{72}$ In addition, BCL2A1 was highly expressed in mantle cell lymphoma ${ }^{71}$ and multiple types of large B-cell lymphoma, ${ }^{73-75}$ especially the OxPhos subgroup of diffuse large B-cell lymphoma. ${ }^{76}$

When first identified, human BCL2A1 mRNA was overexpressed in stomach cancer as compared with normal tissue, indicating a possible function of BCL2A1 also in solid tumors. ${ }^{47}$ High mRNA expression in solid tumor tissues was confirmed in other studies, for example, by northern blot analysis in stomach and colon cancer. ${ }^{77}$ Among a panel of solid tumor tissues of different origins, including breast, colon, lung, ovarian and prostate, the highest expression of BCL2A1 mRNA was detected in breast cancer samples. ${ }^{78}$ Interestingly, in advanced breast cancer a higher expression of $B C L 2 A 1$ mRNA was found when compared with less advanced tumors, ${ }^{79}$ suggesting an association of BCL2A1 expression with later and more severe disease stages. Furthermore, BCL2A1 expression was associated with metastatic disease in melanoma ${ }^{80}$ and hepatocellular carcinoma. ${ }^{81}$ Transcriptional profiling indicated $B C L 2 A 1$ as highly expressed in squamous cell carcinoma of the skin, ${ }^{82}$ and later on, BCL2A1 was observed to be overexpressed in oral squamous cell carcinoma. ${ }^{83}$ In summary, BCL2A1 has been identified as overexpressed in a variety of hematological malignancies as well as solid tumors and appears to be predominantly associated with advanced or metastatic disease stages (Table 1). However, so far most studies have

Table 1 Expression of BCL2A1 in human tumor samples

\begin{tabular}{|c|c|c|c|c|c|c|}
\hline Tumor type & $N$ & mRNA & Protein & Expression in a selective patient group & Method & Reference \\
\hline Acute lymphoblastic leukemia & 16 & $X$ & & & PCR & 71 \\
\hline Acute lymphoblastic leukemia & 9 & $\mathrm{X}$ & & Higher in cortical T-ALL than in pre-T ALL & PCR & 85 \\
\hline Chronic lymphocytic leukemia & 32 & $X$ & & Higher in $11 q$ del patients & PCR & 71 \\
\hline Chronic lymphocytic leukemia & 14 & $X$ & & Higher in fludarabine-resistant patients & Microarray, PCR & 72 \\
\hline Chronic lymphocytic leukemia & 37 & $X$ & & Higher in chemotherapy-resistant patients & PCR & 92 \\
\hline Chronic lymphocytic leukemia & 5 & & $\mathrm{X}$ & & $\mathrm{IHC}$ & 95 \\
\hline Chronic lymphocytic leukemia & 12 & & $\mathrm{X}$ & & Western blot & 103 \\
\hline Acute myeloid leukemia & 27 & $\mathrm{X}$ & & & PCR & 71 \\
\hline Acute myeloid leukemia & $14 / 19$ & $\mathrm{X}$ & & & PCR & 42 \\
\hline Chronic myeloid leukemia & 12 & $\mathrm{X}$ & & & PCR & 71 \\
\hline Mantle cell lymphoma & 19 & $\mathrm{X}$ & & & PCR & 71 \\
\hline Mediastinal large B-cell lymphoma & 176 & $X$ & & & Microarray & 73 \\
\hline Diffuse large B-cell lymphoma & 9 & $\mathrm{X}$ & & & Microarray & 74 \\
\hline Diffuse large B-cell lymphoma & 176 & $\mathrm{x}$ & & Higher in OxPhos patient group & Microarray & 76 \\
\hline Stomach cancer & 8 & $\mathrm{X}$ & & & Northern blot & 56 \\
\hline Stomach cancer & 28 & $\mathrm{X}$ & & Higher in metastatic tumors & Northern blot & 77 \\
\hline Colon adenoma & 15 & $X$ & & & Northern blot & 77 \\
\hline Colon cancer & $3 / 9$ & $\mathrm{X}$ & & & PCR & 78 \\
\hline Breast cancer & $8 / 9$ & $\mathrm{X}$ & & & PCR & 78 \\
\hline Breast cancer & 30 & $X$ & & Higher in advanced tumors & PCR & 79 \\
\hline Breast cancer & 150 & $X$ & & Associated with poor treatment outcome & Microarray & 93 \\
\hline Melanoma & 82 & $X$ & & Higher in metastatic tumors & Microarray & 80 \\
\hline Hepatocellular carcinoma & 32 & $X$ & & Higher in metastatic tumors & Microarray, PCR & 81 \\
\hline Skin squamous cell carcinoma & 5 & $\mathrm{X}$ & & & Microarray & 82 \\
\hline Oral squamous cell carcinoma & 43 & $X$ & $X$ & & Microarray, IHC & 83 \\
\hline
\end{tabular}

Abbreviations: IHC, immunohistochemistry; $N$, number of primary tissue samples. Overview of the studies investigating the expression of BCL2A1 mRNA and proteins in human tumor samples. 
analyzed mRNA expression levels, and only little data are available on BCL2A1 protein expression in tumors, possibly due to the limitations of commercially available antibodies for human BCL2A1.

\section{A Function of BCL2A1 in Tumorigenesis}

The increased BCL2A1 expression in advanced tumor stages indicates that BCL2A1 may facilitate tumor progression. Indeed, a contribution of BCL2A1 to tumorigenesis was demonstrated in anaplastic large cell lymphoma, where the transformation by anaplastic lymphoma kinase was dependent on BCL2A1. ${ }^{75}$ Additional support for the ability of BCL2A1 to transform tumor cells was provided by another study in which BCL2A1 increased E1A-induced transformation. ${ }^{84}$ Similarly, Mandal et al. ${ }^{85}$ suggest that upon deregulated T-cell receptor signaling, BCL2A1 may contribute to the transformation of pre T-cell to cortical acute lymphoblastic leukemia. Ubiquitin-resistant and hence more stable mutants of BCL2A1 have been described to promote lymphoma, highlighting the importance of post-translational regulation of BCL2A1 in a physiological context. ${ }^{86}$ Although not tumorigenic by itself in mice, ${ }^{63}$ enforced expression of BCL2A1 was found to accelerate myc-induced leukemogenesis upon engraftment in mice. However, when compared with other anti-apoptotic BCL2 proteins, the effect of BCL2A1 overexpression on the survival of leukemic mice was less pronounced. ${ }^{78}$ As indicated by a genome profiling study, BCL2A1 may have an important function in squamous cell carcinoma. $^{82}$ Support for an important role of BCL2A1 in oral squamous cell carcinoma was provided by the description of increased expression of BCL2A1 in a stem-cell like side population of oral squamous cell carcinoma, highlighting a potential pro-survival function of BCL2A1 in cancer stem cells. $^{87}$ Taken together, several studies have shown that BCL2A1 may contribute to tumor progression, probably by preventing apoptosis in the advanced tumor cells, which may display more genetic abnormalities and thus may be more dependent on the protection by anti-apoptotic BCL2 proteins.

\section{The Role of BCL2A1 in Chemotherapy Resistance}

Besides a potential role of BCL2A1 in tumorigenesis, a central function of BCL2A1 is to suppress apoptosis upon toxic insults and consequently to prevent cell death upon chemotherapy. In this regard, overexpression of BCL2A1 in cell lines has been shown to mediate resistance to etoposide, ${ }^{88}$ staurosporine $^{89}$ or cisplatin. ${ }^{90}$ Conversely, silencing of BCL2A1 by gene knockdown was found to sensitize malignant B-cell lines to apoptosis induced by chemotherapy or the therapeutic antibody rituximab. ${ }^{91}$ Besides the modulation of expression levels in cell lines, high expression of BCL2A1 in tumor samples has been correlated with in vivo chemoresistance, for example, in chronic lymphocytic leukemia ${ }^{92}$ or breast cancer. ${ }^{93}$ Similarly, BCL2A1 was described to be highly expressed in cisplatin-resistant bladder cancer cell lines. ${ }^{94}$ In a different context, overexpression of BCL2A1 can mediate the resistance to $A B T-737,{ }^{95,96}$ a specific inhibitor of $B C L 2, B C L-X_{L}$ and $B C L-W$, indicating that expression of BCL2A1 may be very important to consider for the successful application of BCL2 inhibitors as novel cancer therapy.

\section{The Potential of BCL2A1 Inhibitors for Cancer Therapy}

Due to their important anti-apoptotic function, BCL2 proteins have been identified as valuable targets for anti-cancer therapy. To this end, several small molecule inhibitors of BCL2 proteins have been developed and are currently tested in clinical trials for multiple malignancies including chronic lymphocytic leukemia. So far, either compounds which inhibit BCL2, BCL- $X_{L}$ and BCL-w, but do not bind MCL1 or BCL2A1, have been presented (ABT-737, Navitoclax), or broadspectrum BCL2 protein inhibitors which bind all anti-apoptotic BCL2 proteins although with varying affinities (eg Obatoclax, apogossypol, TW-37). ${ }^{97}$ However, the specificity of many of these compounds with the exception of ABT-737 and Navitoclax has not been demonstrated, and many potential BCL2 inhibitors might have additional cellular targets resulting in BCL2 protein-independent cell death. ${ }^{98}$ In regards to their toxicity, it may be beneficial to consider selective inhibitors of individual BCL2 proteins rather than broad-spectrum BCL2 inhibitors. In a small compound screen for inhibitors of BCL2A1, gambogic acid was identified as a potential lead compound. ${ }^{99}$ However, gambogic acid also induced cell death in cells that were deficient in the main effector molecules of the BCL2 family, BAX and BAK. Similarly, $N$-aryl maleimides have been identified as potential BCL2A1 inhibitors by highthroughput screening of 66000 compounds and may serve as lead compounds for the development of specific BCL2A1 inhibitors. ${ }^{100}$ Besides these novel potential inhibitors, several apogossypol derivatives may target BCL2A1, ${ }^{101}$ although their specificity for BCL2A1 remains to be demonstrated. Recently, peptide aptamers that specifically target BCL2A1 have been presented, which sensitized malignant $B$-cells to chemotherapeutic drugs, ${ }^{102}$ indicating that a peptide-based targeting strategy might be a promising alternative to small molecule inhibitors. In conclusion, although BCL2A1 is overexpressed in many different types of cancer and the inhibition of BCL2A1 by small molecule inhibitors may be a highly promising strategy for the development of novel anti-cancer therapeutics, so far very few specific and potent inhibitors of BCL2A1 have been described. The lack of selective inhibitors may be explained by the difficulties in targeting specific protein-protein interactions with small molecules and the similarity of the hydrophobic groove found on all anti-apoptotic BCL2 proteins. Therefore, further work is required to fully investigate the potential of BCL2A1 inhibitors for anti-cancer therapy, especially in comparison with other selective inhibitors, for example, for MCL1 or BCL2.

\section{Conflict of Interest}

The author declares no conflict of interest.

Acknowledgements. I would like to thank Gerry Cohen for his guidance and helpful discussion of this manuscript. This study was supported by funding from the Medical Research Council (UK) and Leukaemia and Lymphoma Research (UK). 
1. Irmler M, Thome M, Hahne M, Schneider $P$, Hofmann $K$, Steiner $V$ et al. Inhibition of death receptor signals by cellular FLIP. Nature 1997; 388: 190-195.

2. Thome M, Schneider P, Hofmann K, Fickenscher H, Meinl E, Neipel F et al. Viral FLICEinhibitory proteins (FLIPs) prevent apoptosis induced by death receptors. Nature 1997 386: $517-521$

3. Youle RJ, Strasser A. The BCL-2 protein family: opposing activities that mediate cell death. Nat Rev Mol Cell Biol 2008; 9: 47-59.

4. Labi V, Erlacher M, Kiessling S, Villunger A. BH3-only proteins in cell death initiation, malignant disease and anticancer therapy. Cell Death Differ 2006; 13: 1325-1338.

5. Beroukhim R, Mermel CH, Porter D, Wei G, Raychaudhuri S, Donovan J et al. The landscape of somatic copy-number alteration across human cancers. Nature 2010; 463 : 899-905.

6. Lin EY, Kozak CA, Orlofsky A, Prystowsky MB. The bcl-2 family member, Bcl2a1, maps to mouse chromosome 9 and human chromosome 15. Mamm Genome 1997; 8: 293-294.

7. Choi SS, Park SH, Kim UJ, Shin HS. Bfl-1, a Bcl-2-related gene, is the human homolog of the murine A1, and maps to chromosome 15q24.3. Mamm Genome 1997; 8: 781-782.

8. Herman MD, Nyman T, Welin M, Lehtio L, Flodin S, Tresaugues L et al. Completing the family portrait of the anti-apoptotic Bcl-2 proteins: crystal structure of human $\mathrm{Bfl}-1$ in complex with Bim. FEBS Lett 2008; 582: 3590-3594.

9. Brien G, Debaud AL, Robert X, Oliver L, Trescol-Biemont MC, Cauquil N et al. C-terminal residues regulate localization and function of the antiapoptotic protein $\mathrm{Bfl}-1$. J Biol Chem 2009; 284: 30257-30263.

10. Ko JK, Lee MJ, Cho SH, Cho JA, Lee BY, Koh JS et al. Bfl-1S, a novel alternative splice variant of $\mathrm{Bfl}-1$, localizes in the nucleus via its $\mathrm{C}$-terminus and prevents cell death Oncogene 2003; 22: 2457-2465.

11. Hatakeyama S, Hamasaki A, Negishi I, Loh DY, Sendo F, Nakayama K. Multiple gene duplication and expression of mouse bcl-2-related genes, A1. Int Immunol 1998; 10 : $631-637$

12. Smits $C$, Czabotar PE, Hinds MG, Day CL. Structural plasticity underpins promiscuous binding of the prosurvival protein A1. Structure 2008; 16: 818-829.

13. Tao W, Kurschner C, Morgan Jl. Modulation of cell death in yeast by the Bcl-2 family of proteins. J Biol Chem 1997; 272: 15547-15552.

14. Zhang H, Cowan-Jacob SW, Simonen M, Greenhalf W, Heim J, Meyhack B. Structural basis of BFL-1 for its interaction with BAX and its anti-apoptotic action in mammalian and yeast cells. J Biol Chem 2000; 275: 11092-11099.

15. Sedlak TW, Oltvai ZN, Yang E, Wang K, Boise LH, Thompson CB et al. Multiple Bcl-2 family members demonstrate selective dimerizations with Bax. Proc Natl Acad Sci USA 1995; 92: 7834-7838

16. Zhai D, Jin C, Huang Z, Satterthwait AC, Reed JC. Differential regulation of Bax and Bak by anti-apoptotic Bcl-2 family proteins Bcl-B and Mcl-1. J Biol Chem 2008; 283 9580-9586.

17. Holmgreen SP, Huang DC, Adams JM, Cory S. Survival activity of Bcl-2 homologs Bcl-w and $A 1$ only partially correlates with their ability to bind pro-apoptotic family members. Cell Death Differ 1999; 6: 525-532.

18. Simmons MJ, Fan G, Zong WX, Degenhardt K, White E, Gelinas C. Bfl-1/A1 functions, similar to Mcl-1, as a selective tBid and Bak antagonist. Oncogene 2008; 27: 1421-1428.

19. Werner AB, de Vries $\mathrm{E}$, Tait SW, Bontjer I, Borst J. Bcl-2 family member Bfl-1/A1 sequesters truncated bid to inhibit is collaboration with pro-apoptotic Bak or Bax. J Biol Chem 2002; 277: 22781-22788

20. Willis SN, Chen L, Dewson G, Wei A, Naik E, Fletcher Jl et al. Proapoptotic Bak is sequestered by $\mathrm{Mcl}-1$ and $\mathrm{Bcl}-\mathrm{xL}$, but not Bcl-2, until displaced by $\mathrm{BH} 3-$ only proteins. Genes Dev 2005; 19: 1294-1305.

21. Certo M, Del Gaizo Moore V, Nishino M, Wei G, Korsmeyer S, Armstrong SA et al. Mitochondria primed by death signals determine cellular addiction to antiapoptotic BCL-2 family members. Cancer Cell 2006; 9: 351-365.

22. Chen L, Willis SN, Wei A, Smith BJ, Fletcher JI, Hinds MG et al. Differential targeting of prosurvival $\mathrm{Bcl}-2$ proteins by their $\mathrm{BH} 3-$ only ligands allows complementary apoptotic function. Mol Cell 2005; 17: 393-403.

23. Tse C, Shoemaker AR, Adickes J, Anderson MG, Chen J, Jin S et al. ABT-263: a potent and orally bioavailable Bcl-2 family inhibitor. Cancer Res 2008; 68: 3421-3428.

24. Adams JM, Cory S. The Bcl-2 apoptotic switch in cancer development and therapy. Oncogene 2007; 26: 1324-1337.

25. Kathania M, Raje $\mathrm{Cl}$, Raje M, Dutta RK, Majumdar S. Bfl-1/A1 acts as a negative regulator of autophagy in mycobacteria infected macrophages. Int J Biochem Cell Biol 2011; 43 573-585.

26. Kolluri SK, Zhu X, Zhou X, Lin B, Chen Y, Sun K et al. A short Nur77-derived peptide converts Bcl-2 from a protector to a killer. Cancer Cell 2008; 14: 285-298.

27. Orlofsky A, Berger MS, Prystowsky MB. Novel expression pattern of a new member of the MIP-1 family of cytokine-like genes. Cell Regul 1991; 2: 403-412.

28. Lin EY, Orlofsky A, Berger MS, Prystowsky MB. Characterization of A1, a novel hemopoietic-specific early-response gene with sequence similarity to bcl-2. J Immunol 1993; 151: 1979-1988.

29. Karsan A, Yee E, Harlan JM. Endothelial cell death induced by tumor necrosis factoralpha is inhibited by the Bcl-2 family member, A1. J Biol Chem 1996; 271: 27201-27204.

30. Karsan A, Yee E, Kaushansky K, Harlan JM. Cloning of human Bcl-2 homologue: inflammatory cytokines induce human A1 in cultured endothelial cells. Blood 1996; 87: 3089-3096.
31. Zong WX, Edelstein LC, Chen C, Bash J, Gelinas C. The prosurvival Bcl-2 homolog $\mathrm{Bfl}-1 / \mathrm{A} 1$ is a direct transcriptional target of NF-kappaB that blocks TNFalpha-induced apoptosis. Genes Dev 1999; 13: 382-387.

32. Grumont RJ, Rourke IJ, Gerondakis S. Rel-dependent induction of $A 1$ transcription is required to protect B cells from antigen receptor ligation-induced apoptosis. Genes Dev 1999; 13: 400-411.

33. Lee HH, Dadgostar H, Cheng $Q$, Shu J, Cheng G. NF-kappaB-mediated up-regulation of $\mathrm{Bcl}-\mathrm{x}$ and $\mathrm{Bfl}-1 / \mathrm{A} 1$ is required for $\mathrm{CD} 40$ survival signaling in $\mathrm{B}$ lymphocytes. Proc Natl Acad Sci USA 1999; 96: 9136-9141.

34. Craxton A, Chuang PI, Shu G, Harlan JM, Clark EA. The CD40-inducible Bcl-2 family member A1 protects $B$ cells from antigen receptor-mediated apoptosis. Cell Immunol 2000; 200: 56-62.

35. Kater AP, Evers LM, Remmerswaal EB, Jaspers A, Oosterwijk MF, van Lier RA et al. CD40 stimulation of B-cell chronic lymphocytic leukaemia cells enhances the antiapoptotic profile, but also Bid expression and cells remain susceptible to autologous cytotoxic T-lymphocyte attack. Br J Haematol 2004; 127: 404-415.

36. Morgan RK, Kingham PJ, Walsh MT, Curran DR, Durcan N, McLean WG et al. Eosinophil adhesion to cholinergic IMR-32 cells protects against induced neuronal apoptosis. J Immunol 2004; 173: 5963-5970.

37. $\mathrm{He} \mathrm{CH}$, Waxman $\mathrm{AB}$, Lee $\mathrm{CG}$, Link $\mathrm{H}$, Rabach ME, Ma B et al. Bcl-2-related protein $\mathrm{A} 1$ is an endogenous and cytokine-stimulated mediator of cytoprotection in hyperoxic acute lung injury. J Clin Invest 2005; 115: 1039-1048.

38. Kim H, Kim YN, Kim CW. Oxidative stress attenuates Fas-mediated apoptosis in Jurkat $T$ cell line through Bfl-1 induction. Oncogene 2005; 24: 1252-1261.

39. Liu TX, Zhang JW, Tao J, Zhang RB, Zhang QH, Zhao CJ et al. Gene expression networks underlying retinoic acid-induced differentiation of acute promyelocytic leukemia cells. Blood 2000; 96: 1496-1504.

40. Jing Y, Wang L, Xia L, Chen GQ, Chen Z, Miller WH et al. Combined effect of all-trans retinoic acid and arsenic trioxide in acute promyelocytic leukemia cells in vitro and in vivo. Blood 2001; 97: 264-269.

41. Rasooly R, Schuster GU, Gregg JP, Xiao JH, Chandraratna RA, Stephensen CB. Retinoid $x$ receptor agonists increase bcl2a1 expression and decrease apoptosis of naive T lymphocytes. J Immunol 2005; 175: 7916-7929.

42. Simpson LA, Burwell EA, Thompson KA, Shahnaz S, Chen AR, Loeb DM. The antiapoptotic gene A1/BFL1 is a WT1 target gene that mediates granulocytic differentiation and resistance to chemotherapy. Blood 2006; 107: 4695-4702.

43. Jenal M, Batliner J, Reddy VA, Haferlach T, Tobler A, Fey MF et al. The anti-apoptotic gene BCL2A1 is a novel transcriptional target of PU1. Leukemia 2010; 24: 1073-1076.

44. Shaffer AL, Lin KI, Kuo TC, Yu X, Hurt EM, Rosenwald A et al. Blimp-1 orchestrates plasma cell differentiation by extinguishing the mature $B$ cell gene expression program. Immunity 2002; 17: 51-62.

45. Herold MJ, Zeitz J, Pelzer C, Kraus C, Peters A, Wohlleben G et al. The stability and anti-apoptotic function of $A 1$ are controlled by its $C$ terminus. J Biol Chem 2006; 281 : 13663-13671.

46. Kucharczak JF, Simmons MJ, Duckett CS, Gelinas C. Constitutive proteasome-mediated turnover of $\mathrm{Bfl}-1 / \mathrm{A} 1$ and its processing in response to TNF receptor activation in FL5.12 pro-B cells convert it into a prodeath factor. Cell Death Differ 2005: 12: 1225-1239.

47. Choi SS, Park IC, Yun JW, Sung YC, Hong SI, Shin HS. A novel Bcl-2 related gene, Bfl-1, is overexpressed in stomach cancer and preferentially expressed in bone marrow. Oncogene 1995; 11: 1693-1698.

48. Noble KE, Wickremasinghe RG, DeCornet C, Panayiotidis P, Yong KL. Monocytes stimulate expression of the $\mathrm{Bcl}-2$ family member, $\mathrm{A} 1$, in endothelial cells and confer protection against apoptosis. J Immunol 1999; 162: 1376-1383.

49. Kenny JJ, Knobloch TJ, Augustus M, Carter KC, Rosen CA, Lang JC. GRS, a novel member of the Bcl-2 gene family, is highly expressed in multiple cancer cell lines and in normal leukocytes. Oncogene 1997; 14: 997-1001.

50. Xiang Z, Ahmed AA, Moller C, Nakayama K, Hatakeyama S, Nilsson G. Essential role of the prosurvival bcl-2 homologue $\mathrm{A} 1$ in mast cell survival after allergic activation. J Exp Med 2001; 194: 1561-1569.

51. Xiang Z, Moller C, Nilsson G. IgE-receptor activation induces survival and Bfl-1 expression in human mast cells but not basophils. Allergy 2006; 61: 1040-1046.

52. Karlberg M, Xiang Z, Nilsson G. Fc gamma RI-mediated activation of human mast cells promotes survival and induction of the pro-survival gene Bfl-1. J Clin Immunol 2008; 28: $250-255$

53. Su TT, Rawlings DJ. Transitional B lymphocyte subsets operate as distinct checkpoints in murine splenic B cell development. J Immunol 2002; 168: 2101-2110.

54. Tomayko MM, Cancro MP. Long-lived $B$ cells are distinguished by elevated expression of A1. J Immunol 1998; 160: 107-111.

55. Tomayko MM, Punt JA, Bolcavage JM, Levy SL, Allman DM, Cancro MP. Expression of the Bcl-2 family member A1 is developmentally regulated in T cells. Int Immunol 1999; 11: 1753-1761.

56. Verschelde C, Walzer T, Galia P, Biemont MC, Quemeneur L, Revillard JP et al. A1/Bfl-1 expression is restricted to TCR engagement in T lymphocytes. Cell Death Differ 2003; 10: 1059-1067.

57. Tarte K, Jourdan M, Veyrune JL, Berberich I, Fiol G, Redal $\mathrm{N}$ et al. The Bcl-2 family member Bfl-1/A1 is strongly repressed in normal and malignant plasma cells but is a potent anti-apoptotic factor for myeloma cells. Br J Haematol 2004; 125: 373-382. 
58. Jourdan M, Reme T, Goldschmidt H, Fiol G, Pantesco V, De Vos J et al. Gene expression of anti- and pro-apoptotic proteins in malignant and normal plasma cells. $\mathrm{Br} \mathrm{J}$ Haematol 2009; 145: 45-58.

59. Martinon F, Burns K, Tschopp J. The inflammasome: a molecular platform triggering activation of inflammatory caspases and processing of prolL-beta. Mol Cell 2002; 10 : 417-426.

60. Schroder K, Tschopp J. The inflammasomes. Cell 2010; 140: 821-832.

61. Capuco AV, Li M, Long E, Ren S, Hruska KS, Schorr K et al. Concurrent pregnancy retards mammary involution: effects on apoptosis and proliferation of the mammary epithelium after forced weaning of mice. Biol Reprod 2002; 66: 1471-1476.

62. Thangaraju M, Sharan S, Sterneck E. Comparison of mammary gland involution between 129S1 and C57BL/6 inbred mouse strains: differential regulation of Bcl2a1, Trp53, Cebpb, and Cebpd expression. Oncogene 2004; 23: 2548-2553.

63. Chuang PI, Morefield S, Liu CY, Chen S, Harlan JM, Willerford DM. Perturbation of B-cell development in mice overexpressing the Bcl-2 homolog A1. Blood 2002; 99: 3350-3359.

64. Gonzalez J, Orlofsky A, Prystowsky MB. A1 is a growth-permissive antiapoptotic factor mediating postactivation survival in T cells. Blood 2003; 101: 2679-2685.

65. Verschelde C, Michonneau D, Trescol-Biemont MC, Berberich I, Schimpl A, BonnefoyBerard N. Overexpression of the antiapoptotic protein A1 promotes the survival of double positive thymocytes awaiting positive selection. Cell Death Differ 2006; 13: 1213-1221.

66. McDonnell TJ, Korsmeyer SJ. Progression from lymphoid hyperplasia to high-grade malignant lymphoma in mice transgenic for the $t(14 ; 18)$. Nature $1991 ; 349$ 254-256.

67. Motoyama N, Wang F, Roth KA, Sawa H, Nakayama K, Negishi I et al. Massive cell death of immature hematopoietic cells and neurons in Bcl-x-deficient mice. Science 1995; 267 1506-1510.

68. Rinkenberger JL, Horning S, Klocke B, Roth K, Korsmeyer SJ. Mcl-1 deficiency results in peri-implantation embryonic lethality. Genes Dev 2000; 14: 23-27.

69. Hamasaki A, Sendo F, Nakayama K, Ishida N, Negishi I, Hatakeyama S. Accelerated neutrophil apoptosis in mice lacking A1-a, a subtype of the bcl-2-related A1 gene. J Exp Med 1998; 188: 1985-1992.

70. Oberdoerffer P, Kanellopoulou C, Heissmeyer V, Paeper C, Borowski C, Aifantis I et al. Efficiency of RNA interference in the mouse hematopoietic system varies between cell types and developmental stages. Mol Cell Biol 2005; 25: 3896-3905.

71. Nagy B, Lundan T, Larramendy ML, Aalto Y, Zhu Y, Niini T et al. Abnormal expression of apoptosis-related genes in haematological malignancies: overexpression of MYC is poor prognostic sign in mantle cell lymphoma. Br J Haematol 2003; 120: 434-441.

72. Morales AA, Olsson A, Celsing F, Osterborg A, Jondal M, Osorio LM. High expression of bfl-1 contributes to the apoptosis resistant phenotype in B-cell chronic lymphocytic leukemia. Int J Cancer 2005; 113: 730-737.

73. Feuerhake F, Kutok JL, Monti S, Chen W, LaCasce AS, Cattoretti G et al. NFkappaB activity, function, and target-gene signatures in primary mediastinal large B-cell lymphoma and diffuse large B-cell lymphoma subtypes. Blood 2005; 106: 1392-1399.

74. Mahadevan D, Spier C, Della Croce K, Miller S, George B, Riley C et al. Transcript profiling in peripheral T-cell lymphoma, not otherwise specified, and diffuse large B-cell lymphoma identifies distinct tumor profile signatures. Mol Cancer Ther 2005; 4 1867-1879.

75. Piva R, Pellegrino E, Mattioli M, Agnelli L, Lombardi L, Boccalatte $F$ et al. Functiona validation of the anaplastic lymphoma kinase signature identifies CEBPB and BCL2A1 as critical target genes. J Clin Invest 2006; 116: 3171-3182.

76. Monti S, Savage KJ, Kutok JL, Feuerhake F, Kurtin P, Mihm M et al. Molecular profiling of diffuse large B-cell lymphoma identifies robust subtypes including one characterized by host inflammatory response. Blood 2005; 105: 1851-1861.

77. Park IC, Lee SH, Whang DY, Hong WS, Choi SS, Shin HS et al. Expression of a nove $\mathrm{Bcl}-2$ related gene, Bfl-1, in various human cancers and cancer cell lines. Anticancer Res 1997; 17: 4619-4622.

78. Beverly LJ, Varmus HE. MYC-induced myeloid leukemogenesis is accelerated by all six members of the antiapoptotic BCL family. Oncogene 2009; 28: 1274-1279.

79. Yoon HS, Hong SH, Kang HJ, Ko BK, Ahn SH, Huh JR. Bfl-1 gene expression in breast cancer: its relationship with other prognostic factors. J Korean Med Sci 2003; 18: 225-230.

80. Riker Al, Enkemann SA, Fodstad O, Liu S, Ren S, Morris C et al. The gene expression profiles of primary and metastatic melanoma yields a transition point of tumor progression and metastasis. BMC Med Genomics 2008; 1: 13.
81. Lee CF, Ling ZQ, Zhao T, Fang SH, Chang WC, Lee SC et al. Genomic-wide analysis of lymphatic metastasis-associated genes in human hepatocellular carcinoma. World J Gastroenterol 2009; 15: 356-365.

82. Kathpalia VP, Mussak EN, Chow SS, Lam PH, Skelley N, Time M et al. Genome-wide transcriptional profiling in human squamous cell carcinoma of the skin identifies unique tumor-associated signatures. J Dermatol 2006; 33: 309-318.

83. Saleh A, Zain RB, Hussaini H, Ng F, Tanavde V, Hamid S et al. Transcriptional profiling of oral squamous cell carcinoma using formalin-fixed paraffin-embedded samples. Oral Oncol 2010; 46: 379-386.

84. D'Sa-Eipper C, Subramanian T, Chinnadurai G. bfl-1, a bcl-2 homologue, suppresses p53-induced apoptosis and exhibits potent cooperative transforming activity. Cancer Res 1996; 56: 3879-3882.

85. Mandal M, Borowski C, Palomero T, Ferrando AA, Oberdoerffer P, Meng F et al. The $B C L 2 A 1$ gene as a pre-T cell receptor-induced regulator of thymocyte survival. J Exp Med 2005; 201: 603-614.

86. Fan G, Simmons MJ, Ge S, Dutta-Simmons J, Kucharczak J, Ron Y et al. Defective ubiquitin-mediated degradation of antiapoptotic Bfl-1 predisposes to lymphoma. Blood 2010; 115: 3559-3569.

87. Yajima T, Ochiai H, Uchiyama T, Takano N, Shibahara T, Azuma T. Resistance to cytotoxic chemotherapy-induced apoptosis in side population cells of human oral squamous cell carcinoma cell line Ho-1-N-1. Int J Oncol 2009; 35: 273-280.

88. Wang CY, Guttridge DC, Mayo MW, Baldwin Jr AS. NF-kappaB induces expression of the $\mathrm{Bcl}-2$ homologue $\mathrm{A} 1 / \mathrm{Bfl}-1$ to preferentially suppress chemotherapy-induced apoptosis. Mol Cell Biol 1999; 19: 5923-5929.

89. Shim YH, Byun EK, Lee MJ, Huh J, Kim CW. Anti-apoptotic role of Bfl-1 in staurosporinetreated B-lymphoblastic cells. Int J Hematol 2000; 72: 484-490.

90. Cheng $\mathrm{Q}$, Lee HH, Li Y, Parks TP, Cheng G. Upregulation of Bcl-x and Bfl-1 as a potential mechanism of chemoresistance, which can be overcome by NF-kappaB inhibition. Oncogene 2000; 19: 4936-4940.

91. Brien G, Trescol-Biemont MC, Bonnefoy-Berard N. Downregulation of Bfl-1 protein expression sensitizes malignant $B$ cells to apoptosis. Oncogene 2007; 26: 5828-5832.

92. Olsson A, Norberg M, Okvist A, Derkow K, Choudhury A, Tobin G et al. Upregulation of bfl-1 is a potential mechanism of chemoresistance in B-cell chronic lymphocytic leukaemia. Br J Cancer 2007; 97: 769-777.

93. Campone M, Campion L, Roche H, Gouraud W, Charbonnel C, Magrangeas F et al. Prediction of metastatic relapse in node-positive breast cancer: establishment of clinicogenomic model after FEC100 adjuvant regimen. Breast Cancer Res Treat 2008; 109: 491-501

94. Kim JK, Kim KD, Lee E, Lim JS, Cho HJ, Yoon HK et al. Up-regulation of Bfl-1/A1 via NF-kappaB activation in cisplatin-resistant human bladder cancer cell line. Cancer Lett 2004; 212: 61-70.

95. Vogler M, Butterworth M, Majid A, Walewska RJ, Sun XM, Dyer MJ et al. Concurrent upregulation of $B C L-X L$ and $B C L 2 A 1$ induces $\sim 1000$-fold resistance to ABT-737 in chronic lymphocytic leukemia. Blood 2009; 113: 4403-4413.

96. Yecies D, Carlson NE, Deng J, Letai A. Acquired resistance to ABT-737 in lymphoma cells that up-regulate MCL-1 and BFL-1. Blood 2010; 115: 3304-3313.

97. Vogler M, Dinsdale D, Dyer MJ, Cohen GM. Bcl-2 inhibitors: small molecules with a big impact on cancer therapy. Cell Death Differ 2009; 16: 360-367.

98. Vogler M, Weber K, Dinsdale D, Schmitz I, Schulze-Osthoff K, Dyer MJ et al. Different forms of cell death induced by putative BCL2 inhibitors. Cell Death Differ 2009; 16: 1030-1039.

99. Zhai D, Jin C, Shiau CW, Kitada S, Satterthwait AC, Reed JC. Gambogic acid is an antagonist of antiapoptotic Bcl-2 family proteins. Mol Cancer Ther 2008; 7: 1639-1646.

100. Cashman JR, MacDonald M, Ghirmai S, Okolotowicz KJ, Sergienko E, Brown B et al. Inhibition of Bfl-1 with N-aryl maleimides. Bioorg Med Chem Lett 2010; 20: 6560-6564.

101. Wei J, Kitada S, Rega MF, Emdadi A, Yuan H, Cellitti J et al. Apogossypol derivatives as antagonists of antiapoptotic Bcl-2 family proteins. Mol Cancer Ther 2009; 8: 904-913.

102. Brien G, Debaud AL, Bickle M, Trescol-Biemont MC, Moncorge O, Colas $P$ et al. Characterization of peptide aptamers targeting Bfl-1 anti-apoptotic protein. Biochemistry 2011; 50: 5120-5129.

103. Tromp JM, Tonino SH, Elias JA, Jaspers A, Luijks DM, Kater AP et al. Dichotomy in $\mathrm{NF}$-kappaB signaling and chemoresistance in immunoglobulin variable heavy-chainmutated versus unmutated CLL cells upon CD40/TLR9 triggering. Oncogene 2010; 29 : 5071-5082. 